Paper

\title{
Experimentation and Evaluation of a Multimedia Exhibition Information Service Using Visitor-owned Portable Wi-Fi Terminals Suitable for Small-scale Mu- seums
}

\author{
Takuzi Suzuki ${ }^{\dagger} \dagger^{\dagger}$, Fumio Adachi (member) ${ }^{\dagger}$, Yoshitsugu Manabe (member) ${ }^{\dagger \dagger}$
}

\begin{abstract}
Several excellent multimedia museum information services using portable terminals are proposed, but are very difficult to introduce for small-scale museums that have limited human and capital resources.

The experimentation of a simple multimedia exhibition information service using visitor-owned portable Wi-Fi terminals was carried out on a special exhibition of the National Museum of Japanese History in the summer of 2013. It is easy to imitate and will be able to extend more advanced contents.

We have two analyses to evaluate visitors' reaction and acceptance of the service. An analysis of visitor questionnaire survey clarified that there are many users who cannot do a setup of Wi-Fi well beyond our anticipation, and that young women positively accepts the service. An analysis of web access logs revealed that the users tend to select a content not by its meaning but a location of the link to the contents on the screen.
\end{abstract}

Key words: multimedia exhibition information service, visitor-owned portable Wi-Fi terminal, smartphone, tablet terminal, small-scale museum

\section{Introduction}

Portable terminals including smartphones and tablet terminals have enough potential to use for multimedia museum information services. Several excellent applications for the museums using portable terminals are proposed, but, at present, most of them are very difficult to introduce for small-scale museums that have limited human and capital resources.

In this paper, a simple solution of multimedia exhibition information service using visitor-owned portable Wi-Fi terminals suitable for small-scale museums is deduced. The service is easy to imitate or refer, and will be able to extend more advanced contents. The experimentation to demonstrate the effectiveness of the service was carried out on a special exhibition of the National Museum of Japanese History, Chiba, JAPAN in the summer of 2013.

We have two analyses to evaluate visitors' reaction and acceptance of the service. One is an analysis of a

Received December 15, 2013; Revised March 13, 2014; Accepted May 3,2014

$\dagger$ National Museum of Japanese History

(Chiba, Japan)

$\dagger \dagger$ Graduate School of Advanced Integration Science, Chiba University

(Chiba, Japan) visitor questionnaire survey to know visitors' response immediately, and another is an analysis of web access logs to probe unconscious actions of visitors. This paper also shows the result of two analyses.

\section{Evolution of museum information ser- vice using portable terminals}

Providing museum information by using portable terminals is not novel. A rental service of audio guide terminal is popularly prepared in most museums. The National Museum of Japanese History introduced the first version of audio guide service for permanent exhibitions in 1994.

Several excellent multimedia exhibition information services using museum-prepared portable terminals are proposed $^{12)}$. "MINPAKU Digital Guide ${ }^{3) "}$ which is introduced by the National Museum of Ethnology, Osaka, JAPAN in 1999, is one of pioneer works. This is a portable device that lets you select video and audio explanations of the exhibits you see while visiting the museum. Recently, a multimedia exhibition information service using Nintendo 3DS "The Audioguide Louvre - Nintendo 3DS" was available at the Louvre Museum, Paris, FRANCE in April, 2012 ${ }^{4}$. This service is the joint product of the Louvre Museum and Nintendo Co., Ltd and includes several tour programs, location 
estimation technology, high definition photographs and $3 \mathrm{D}$ viewing of major pieces, etc.

The use of visitor-owned portable terminals including smartphones and tablet terminals are rapidly spreading. Such terminals have enough ability to play various kinds of multimedia contents. Some museums have already tried to use the terminals as a personal exhibition guide 5)6). At the Tokyo National Museum, Tokyo, JAPAN, three kinds of application "e-Museum," "Tokyo National Museum: 30-minute Tour of the Gallery of Horyuji Treasures," and "Tohakunavi" are available to download and install ${ }^{7}$. The National Museum of Western Art, Tokyo, JAPAN released an official museum application "Touch the Museum" in 2010). In every case, a certain application software for access to exhibition information is provided. This software uses advanced function of portable terminals such as precise location detection, QR code reading, augmented reality, etc.

\section{Practical solution for small-scale mu- seums}

In this section, we discuss several requirements of a museum information service using visitor-owned portable terminals for small-scale museums that have limited human and capital resources, and deduce a simple solution to satisfy the requirements. The solution should be easy to imitate or refer by the museums.

In many cases, preparation of an audio guide is limited to the permanent exhibition to which it can count upon prolonged use, or the special exhibition with abundant reserve assets. The expense for maintenances of the hardware is necessary to continue service to rent terminals; disinfecting of used equipments, checking breakdowns, preparation to loss or theft, etc. The expense for developments of the software cannot also be overlooked.

The use of visitor-owned portable terminals for museum information service gives advantage in both the museum and visitors: the museum is released from maintenance of the hardware and can make efforts in the development of the superior software, and visitors can use the favorite portable terminals and is not perplexed with the operation.

Introduction of advanced and attractive work that we mentioned in the last session is desired. But it is very difficult from a viewpoint of small-scale museums. First, almost all museums have no ability of development of application programs on their own. The outsourcing cost for the development comes up, and the whole of the contents included in the application could not be taken care. In addition, the cost concerning the maintenance management of the developed application is not small. Second, visitors have to download the application for exhibition information services from certified download site and install. Registration of the application to the download site takes the time for several days because the safety and reliability of the application are verified. The schedule for development of application must have enough margin times, and it is very difficult to correct the mistake after the application was distributed.

From the above discussion, requirements of a museum information service using visitor-owned portable terminals are summarized below:

- running costs are small;

- visitors don't need any preparation before coming to the museum;

- museum staffs can perform all the work to do the service by themselves, and outsourcing of whole or partial work is available; and

- change of the provided contents is always possible, and the display of a terminal can be updated as soon as possible.

As a certain solution that satisfies the requirements, the use of a combination of a web browser and a wireless connection network is deduced. Almost all portable terminals have the ability to access a Wi-Fi network and reproduce the web contents. The solution is easy to imitate or refer because most museums have their own museum website, and same skill can be used to edit the HTML contents.

The HTML5 ${ }^{9)}$ technology will make advanced multimedia information services available in various kinds of terminals. But, at present, it is difficult to develop HTML5 contents which are equally reproduced in every terminal because there are various implementations of the web browser supporting HTML5 tags partially. The use of the HTML5 technology is our next challenge and was excluded from this paper. Announcement of the final recommendation of HTML5 is strongly desired. The solution we deduced is able to extend HTML5 contents easily.

\section{Experimentation}

\section{1 Contents}

To demonstrate the suitability of deduced solution practically, an experimentation was carried out in a special exhibition "Musical Instruments Tell Stories ${ }^{10)}$ " in 


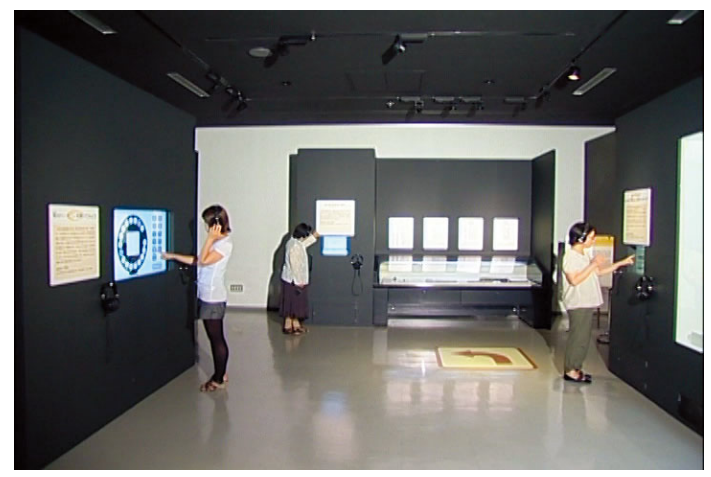

Fig. 1 Some touchpanel PC terminals in the gagaku section.

the National Museum of Japanese History in the summer of 2013. The period of the experimentation was the same as the period of the special exhibition (49 days).

In the exhibition, for more close understanding about Japanese musical instruments, a section for introducing gagaku — Japanese ancient court music (and dance) that the instruments were used was arranged in the special exhibition room B. Multimedia contents were developed and provided using 5 touchpanel PC terminal for help of visitor's understanding about gagaku. Some PC terminals used in the exhibition can be seen in Fig. 1.

Every PC terminal has two headphones, and visitors listen the sound via the headphone to keep the exhibition room quiet. So the number of visitors that can listen the sound simultaneously was restricted. It was one of motive to do the experimentation to enable to listen the sound whenever they desired.

41 audio contents and 3 movie contents are provided via portable terminals. It is the same contents that is provided from PC terminals. Because we were allowed to do the experimentation on condition that every visitor is able to get the same amount of information whether the visitor has a own portable terminal or not. Unfortunately, the functions of free sound mixing providing by some PC terminals were not available on portable terminals, and the quality of audio/video contents was adjusted suitably to control the load of traffic. Audio data have MP3 format (192kbps CBR), and movie data have MP4 format (Apple TV H.264 480p).

To keep quiet, in addition to a portable terminal, a self preparation of a headphone was requested. A few complaints (e.g. a headphone should be sold at a museum shop) are received. (It is a point to be improved in the next trial.)
Details of each content are shown in Appendix A.

\section{2 Environment}

Fig. 2 shows the arrangement of a web server and Wi-Fi equipments. All of them are not special, not expensive, and easy to purchase. A web server and a $\mathrm{Wi}-\mathrm{Fi}$ router are located in the accessway between the special exhibition room $\mathrm{A}$ and $\mathrm{B}$, and two Wi-Fi repeater are located in each room. As the Wi-Fi router and repeater, three Buffalo WZR-HP-G302H were used. The equipments support the function of WDS (Wireless Distribution System) and cover the whole of the special exhibition as a service area.

Fig. 3 shows the Wi-Fi network diagram. SSID is "gakki". The Wi-Fi network was not connected to the Internet and was used only as a private network to keep a minimum security. No Wi-Fi encryption was used to escape the input of Wi-Fi encryption key.

IIS6 on Windows XP was used as a web server program. The URL of web server was http://gakki. In order to input simply, the URL was shortened as much as possible.

An announcement poster of the experimentation was prepared (Fig. 4). Contents of the poster are

- Object of the experimentation,

- What you can do,

- When and Where,

- Equipments to prepare, and

- How to access the contents.

QR code of the URL was presented on the poster.

A visual instruction sheet for connection of the terminal to Wi-Fi network was also prepared(Fig. 5). The following two steps are explained with some hardcopies of the screen:

- Choice of the SSID; and

- Access to the top page.

During the exhibition, all equipments work with no trouble.

\section{Analysis of visitor questionnaire sur- vey}

To know visitors' response immediately, questionnaires are prepared in special exhibition area for investigation of visitors who use our information service using visitor-own portable terminals.

Questions included in the questionnaire are:

(1) sex (male or female),

( 2 ) age (until 10, 11-20, 21-30, 31-40, 41-50, 51-60, 61-70, over 71),

(3) Q. Were you attend this experimentation? 


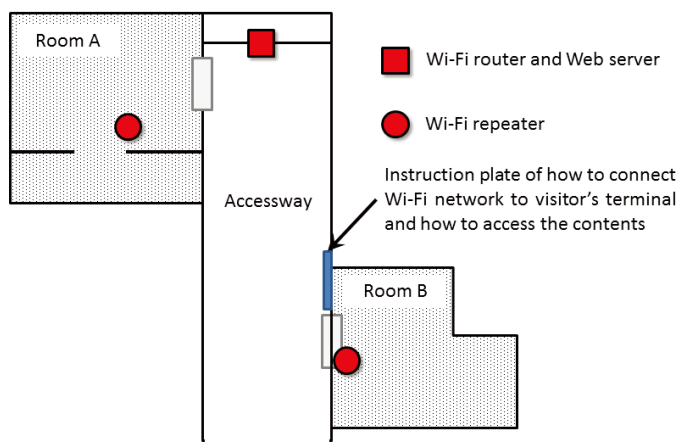

Fig. 2 Arrangement of web server and Wi-Fi equipments.

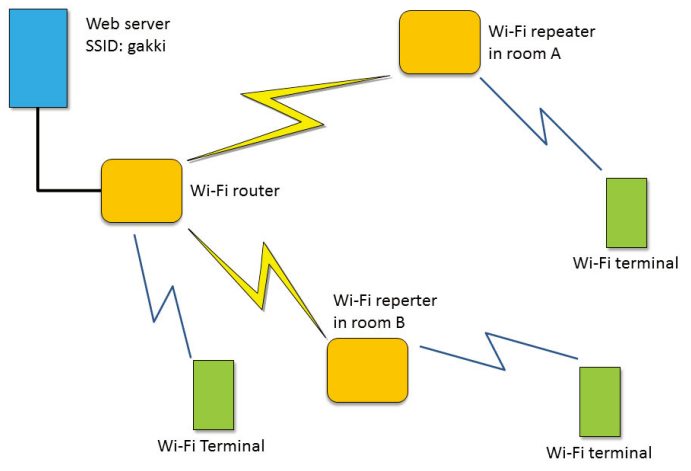

Fig. 3 Wi-Fi network diagram.

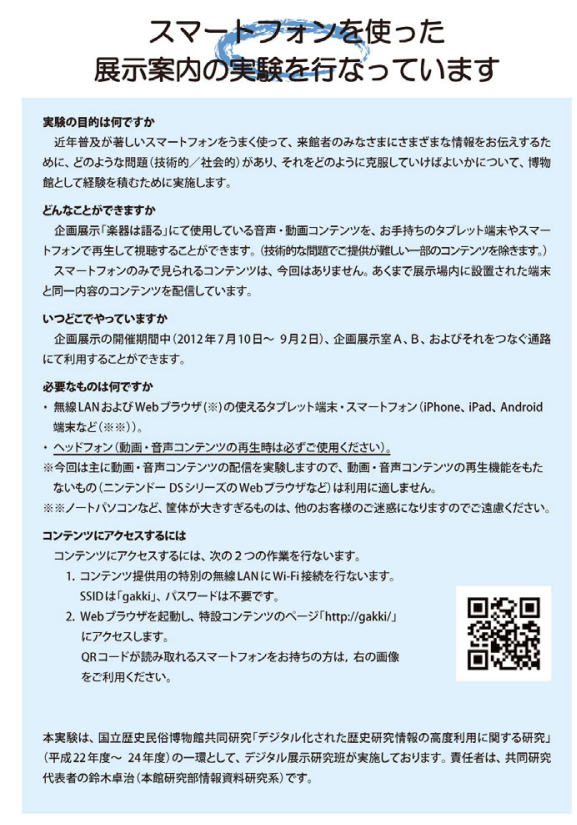

Fig. 4 Poster of announcement.

(yes or no),

(4) Q. Could you set up your terminal? (yes or no),

(5) Q. Could you reproduce our contents? (yes or no), and

(6) Q. Did you enjoy our contents? (yes or no). 46 visitors filled out a questionnaire within the period

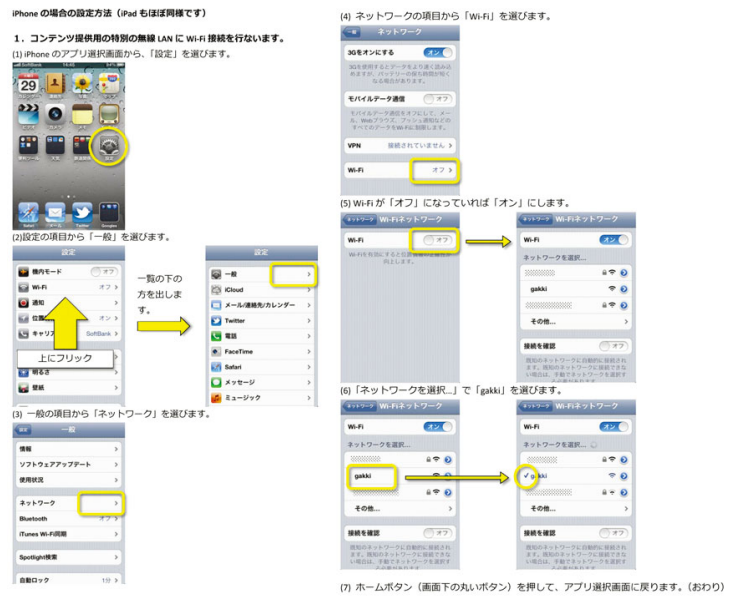

(a) Choice the SSID

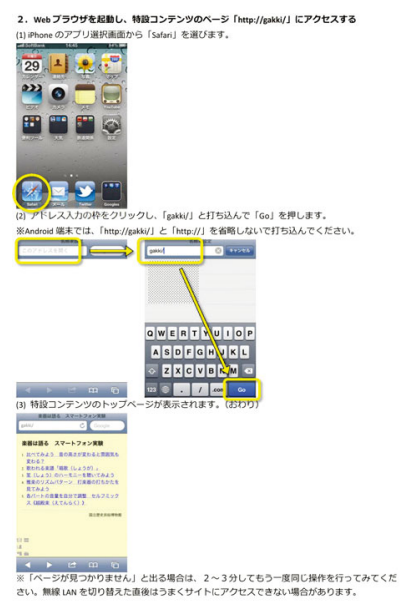

(b) Access the top page

Fig. 5 Instruction of how to connect $\mathrm{Wi}-\mathrm{Fi}$ and access the contents.

of the special exhibition.

Table 1 shows that the relationship between sex and age. At 50 or less-year-old person occupies approximately $90 \%$ of the whole. The number of replies has more females(21) than males(10). The number of most one was 9 for teenage(11-20) females. It is interesting that young women shew stronger concern. It seems that this result is deeply related to how portable terminals are being accepted by society. Major visitors of the museum are older men, and it is one of important problems of the museum to attract more wide range of visitors. The result suggests a possibility of exploitation of new visitors by the use of visitor-owned portable terminals.

Table 2 shows that 4 questions to visitors and answers. Since there were few investigation numbers, it observed only about the relation with sex. Only $5 / 7$ (approx. 71\%) people in male and 10/15 (approx. 67\%) people in female successed to set up his/her portable terminal. It can read in this result that a setup of the portable terminal is not so easy the work for vis- 
Table 1 Relationship between age and sex.

\begin{tabular}{lrrrr}
\hline \multicolumn{1}{c}{ age } & male & female & (no answer) & total \\
\hline-10 & 2 & 4 & 3 & 9 \\
$11-20$ & 2 & 9 & 4 & 15 \\
$21-30$ & 0 & 2 & 2 & 4 \\
$31-40$ & 2 & 3 & 1 & 6 \\
$41-50$ & 2 & 1 & 3 & 6 \\
$51-60$ & 1 & 0 & 2 & 3 \\
$61-70$ & 0 & 1 & 0 & 1 \\
$71-$ & 1 & 0 & 0 & 1 \\
(no answer) & 0 & 1 & 0 & 1 \\
\hline total & 10 & 21 & 15 & 46
\end{tabular}

Table 24 questions to visitors and answers.

\begin{tabular}{lcccr}
\hline & male & female & (no answer) & total \\
\hline Q. Were you attend this experimentation? \\
yes & 7 & 15 & 11 & 33 \\
no & 3 & 6 & 4 & 13 \\
\hline Q. Could you set & up & your terminal? \\
yes & 5 & 10 & 10 & 25 \\
no & 2 & 4 & 0 & 6 \\
(no answer) & 0 & 1 & 1 & 2 \\
\hline Q. Could you reproduce our contents? & \\
yes & 5 & 10 & 9 & 24 \\
no & 0 & 2 & 1 & 3 \\
(no answer) & 2 & 3 & 1 & 6 \\
\hline Q. Did you enjoy our contents? & & \\
yes & 4 & 7 & 6 & 17 \\
no & 0 & 4 & 2 & 6 \\
(no answer) & 3 & 4 & 3 & 10 \\
\hline \multicolumn{5}{l}{}
\end{tabular}

itors even though a visual instruction sheet (Fig. 5) was provided. The result also says that all the people that set up the smart phone reproduced contents and $4 / 5(80 \%)$ people in male and $7 / 10(70 \%)$ people in female enjoyed our contents, and convinces us the effectiveness of the service.

\section{Analysis of web access logs}

To probe unconscious actions of visitors, access logs of IIS6 are analyzed. Table $\mathbf{3}$ shows the number of accesses of each part. There are 2,370 accesses during the special exhibition. The number of contents and the number of accesses isn't in proportion.

We want to see a series of access transition of a user. Some users would look at only few contents. On the other hand, other users would look at many contents comprehensively. Unfortunately, the information about the terminal which accessed contents was not recorded

Table 3 The number of contents and accesses of each part.

\begin{tabular}{rrrcrr}
\hline No. & \multicolumn{2}{c}{ \#contents } & A/V & \multicolumn{2}{c}{ \#access } \\
\hline 1 & 6 & $(13.6 \%)$ & $\mathrm{A}$ & 772 & $(32.6 \%)$ \\
2 & 2 & $(4.5 \%)$ & $\mathrm{V}$ & 206 & $(8.7 \%)$ \\
3 & 26 & $(59.1 \%)$ & $\mathrm{A}$ & 675 & $(28.5 \%)$ \\
4 & 1 & $(2.3 \%)$ & $\mathrm{V}$ & 239 & $(10.1 \%)$ \\
5 & 9 & $(20.5 \%)$ & $\mathrm{A}$ & 478 & $(20.1 \%)$ \\
\hline total & 44 & & & 2370 &
\end{tabular}

Table 4 The frequency and the cumulative relative frequency of the number of accesses in each chunk.

\begin{tabular}{rrr}
\hline \#access & frequency & c.r.freq. \\
\hline 1 & 409 & $56.0 \%$ \\
2 & 111 & $71.2 \%$ \\
3 & 68 & $80.6 \%$ \\
4 & 31 & $84.8 \%$ \\
5 & 18 & $87.3 \%$ \\
6 & 21 & $90.1 \%$ \\
$7-$ & 72 & $100.0 \%$ \\
\hline
\end{tabular}

Table 5 The number of accesses for every part of type A, type B, and type C users.

\begin{tabular}{rrrrrrr}
\hline No. & \multicolumn{2}{c}{$\begin{array}{c}1 \\
\text { type A) }\end{array}$} & \multicolumn{2}{c}{$\begin{array}{c}2-6 \\
\text { (type B) }\end{array}$} & \multicolumn{2}{c}{$\begin{array}{c}7- \\
\text { type C) }\end{array}$} \\
\hline 1 & 98 & $(24.0 \%)$ & 237 & $(30.8 \%)$ & 437 & $(36.6 \%)$ \\
2 & 58 & $(14.2 \%)$ & 80 & $(10.4 \%)$ & 68 & $(5.7 \%)$ \\
3 & 50 & $(12.2 \%)$ & 180 & $(23.4 \%)$ & 448 & $(37.5 \%)$ \\
4 & 113 & $(27.6 \%)$ & 74 & $(9.6 \%)$ & 52 & $(4.3 \%)$ \\
5 & 90 & $(22.0 \%)$ & 199 & $(25.8 \%)$ & 190 & $(15.9 \%)$ \\
\hline total & 409 & & 770 & & 1195 & \\
\hline
\end{tabular}

on access logs. Then, when the lapsed time from the time of one contents being accessed to access of the following contents was less than the threshold value, the same user regarded it as what was accessed continuously, and made "chunks" of data. In this paper, the threshold value was set to 2 minutes* 730 chunks of data were made.

Table 4 shows that the frequency and the cumulative relative frequency of the number of accesses in each chunk. The cumulative relative frequency in one access exceeds $50 \%$, and in six accesses or less, exceeds $90 \%$.

Table 5 shows that the number of accesses for every part about each the case of one access (type A users), the case where access is from 2 times to 6 times (type $\mathrm{B}$ users), and the case where access is 7 times or more (type $\mathrm{C}$ users). A visualization of Table 5 with the relative value of the number of contents of each part is shown in Fig. 6. In case of type B and type C users, the tendency for each part's number of relative accesses to approach the number of relative contents, that is, comprehensive accesses was observed.

Table 6, 7, 8, 9 and 10 show that the number of accesses of the contents of Part 1, 2, 3, 4 and 5 .

It is observed that type $\mathrm{C}$ users accessed every contents comprehensively in every part.

In Part 1, type A and type B users has a tendency to choose a link that is first displayed in several contents which has same category. For example, in the Part 1, pm0.mp3, p3.mp3 and m3.mp3 has same cate-

\footnotetext{
* Making 5 minutes into a threshold value also tried, and the similar result was obtained.
} 


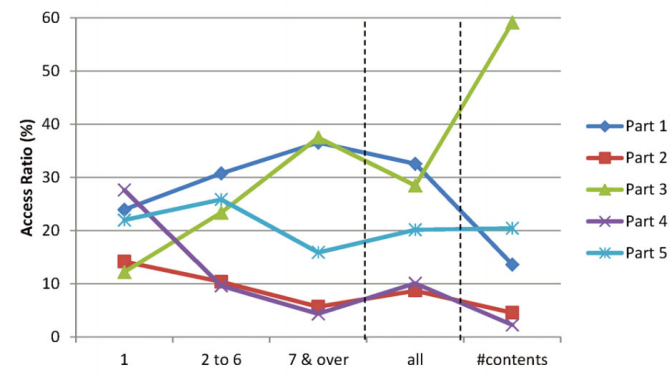

Fig. 6 Visualization of Table 5 with the relative value of the number of contents of each part.

Table 6 The number of accesses of the contents of Part 1 .

\begin{tabular}{lrrrr}
\hline Content & all & A & B & C \\
\hline 1/440Hz.mp3 & 196 & 33 & 85 & 78 \\
1/430Hz.mp3 & 118 & 11 & 37 & 70 \\
1/mixing.mp3 & 125 & 14 & 42 & 69 \\
\hline 1/pm0.mp3 & 141 & 19 & 39 & 83 \\
1/p3.mp3 & 118 & 13 & 23 & 82 \\
1/m3.mp3 & 74 & 8 & 11 & 55 \\
\hline
\end{tabular}

Table 7 The number of accesses of the contents of Part 2.

\begin{tabular}{lrrrr}
\hline Content & all & A & B & C \\
\hline 2/shogaryuteki.mp4 & 149 & 41 & 61 & 47 \\
2/shogahichiriki.mp4 & 57 & 17 & 19 & 21
\end{tabular}

gory (same songs, but each has different pitch) and the link to pm0.mp3 is first displayed (Fig. 7).

In Part 2, shogaryuteki.mp4 was first chosen by all type of users, and only few visitor watched both movies. It is suspected that long reproduction time has affected it.

In Part 3, every link to content is assigned to a corresponding image. In Fig. 8, the number of accesses of every content is written in the position of the corresponding image. In icchiku, the sound of an upper right button was often chosen, and the chord of the upper left button was often chosen in aitake. It can be interpreted that an arrangement of button images determined reproductive frequency for a user, since every sound has the the same grade of interest.

In Part 4, it is mentioned especially that 25 percent of type A users (113/409) chose zundoo.mp4. It suggests that many user watch the movie without interruption. The movie has a long playback time (6:00), and the threshold time to determine a chunk is 2 minutes. Therefore watching of the movie without interruption may count as a chunk of type A user.

In Part 5, it is interesting that biwa was often chosen. It seems that many user had a interest in the sound of biwa.
Table 8 The number of accesses of the contents of Part 3 .

\begin{tabular}{lrrrr}
\hline Content & all & A & B & $\mathrm{C}$ \\
\hline 3/T01.mp3 & 51 & 6 & 14 & 31 \\
3/T02.mp3 & 24 & 0 & 6 & 18 \\
3/T03.mp3 & 19 & 0 & 5 & 14 \\
3/T04.mp3 & 29 & 2 & 1 & 26 \\
3/T05.mp3 & 23 & 3 & 3 & 17 \\
3/T06.mp3 & 22 & 2 & 7 & 13 \\
3/T07.mp3 & 9 & 1 & 0 & 8 \\
3/T08.mp3 & 19 & 2 & 1 & 16 \\
3/T10.mp3 & 11 & 0 & 1 & 10 \\
3/T11.mp3 & 26 & 3 & 1 & 22 \\
3/T12.mp3 & 22 & 0 & 5 & 17 \\
3/T13.mp3 & 10 & 0 & 1 & 9 \\
3/T14.mp3 & 32 & 3 & 10 & 19 \\
3/T15.mp3 & 50 & 7 & 12 & 31 \\
3/T17.mp3 & 54 & 4 & 27 & 23 \\
\hline 3/A01.mp3 & 98 & 5 & 41 & 52 \\
3/A02.mp3 & 58 & 3 & 15 & 40 \\
3/A03.mp3 & 19 & 1 & 8 & 10 \\
3/A04.mp3 & 27 & 4 & 7 & 16 \\
3/A05.mp3 & 10 & 1 & 0 & 9 \\
3/A06.mp3 & 12 & 0 & 1 & 11 \\
3/A07.mp3 & 11 & 1 & 2 & 8 \\
3/A08.mp3 & 11 & 0 & 1 & 10 \\
3/A09.mp3 & 8 & 0 & 2 & 6 \\
3/A10.mp3 & 10 & 0 & 3 & 7 \\
3/A11.mp3 & 10 & 2 & 3 & 5 \\
\hline & & & &
\end{tabular}

Table 9 The number of accesses of the contents of Part 4.

\begin{tabular}{lrrrr}
\hline Content & all & A & B & C \\
\hline 4/zundoo.mp4 & 239 & 113 & 74 & 52 \\
\hline
\end{tabular}

Table 10 The number of accesses of the contents of Part 5.

\begin{tabular}{lrrrr}
\hline Content & all & A & B & C \\
\hline 5/etenraku.mp3 & 161 & 43 & 75 & 43 \\
5/ryuteki.mp3 & 78 & 11 & 38 & 29 \\
5/hichiriki.mp3 & 38 & 5 & 13 & 20 \\
5/sho.mp3 & 42 & 4 & 16 & 22 \\
5/biwa.mp3 & 60 & 12 & 23 & 25 \\
5/so.mp3 & 32 & 7 & 8 & 17 \\
5/kakko.mp3 & 21 & 3 & 5 & 13 \\
5/taiko.mp3 & 23 & 2 & 11 & 10 \\
5/shoko.mp3 & 23 & 3 & 9 & 11 \\
\hline
\end{tabular}

\section{Discussion}

Analysis of visitor questionnaire survey clarified the following three things:

- there are many users who cannot do a setup of WiFi well beyond our anticipation;

- the user who has set up Wi-Fi can access web contents convenient; and

- young women had a strong interest by this experiment.

A problem of the failure of $\mathrm{Wi}-\mathrm{Fi}$ setup should be solved by a suitable standardization. It is necessary to define the standard procedure for making connection with Wi-Fi more simply, and to make it spread with 


\section{「君尔の架楽」高い? 低い?}

いにしえの「君子の薬」は、低い音のほうがよいと考えら れる傾向がありました。基準になる音の高さが変わると、音 楽の印象はどのように変わるでしょうか。

・《越殿楽》を通常の音の高さで聴く。

- 半音3つ分高い音で聴く。

- 半音3つ分低い音で聴く。

Fig. 7 Links to pm0.mp3, p3.mp3 and m3.mp3 in Part 1 .

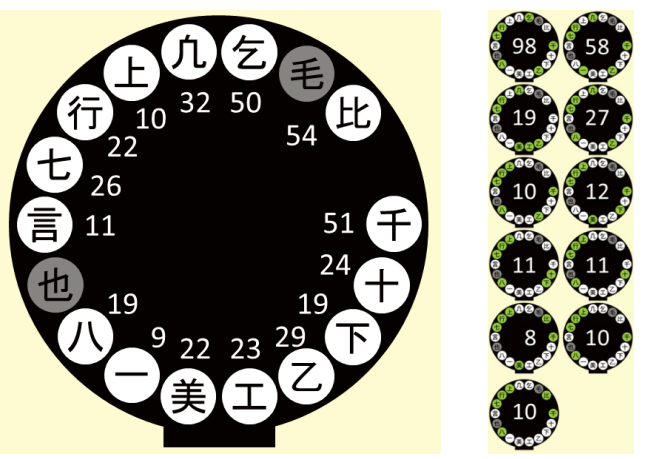

Fig. 8 The number of accesses in the position of the button which reproduces contents in Part 3.

safety secured.

Use of mobile phone network is also effective to avoid the difficulty of Wi-Fi setting. But electric wave of mobile phone cannot be received in many museums. We should maintain environment that the electric wave of mobile phone can be receives in the museum as a social infrastructure.

Web access logs tell that most users choice standing out contents overwhelmingly. That is, although the contents that attracts the strong interest of the user are certainly chosen and are reproduced, the design of a user interface influences operation of a user considerably. The analysis of web access logs effectively works on the evaluation of whether the user interface plays a role as we want.

\section{Conclusion}

A simple solution of multimedia exhibition information services using visitor-owned portable Wi-Fi terminals was deduced. This solution will be easy to imitate or refer from small-scale museums.

An experimentation was carried out to demonstrated the suitability of the solution practically in a special exhibition of the National Museum of Japanese History.

We have two analyses to evaluate visitors' reaction and acceptance of the service. An analysis of visitor questionnaire survey clarified that there are many users who cannot do a setup of Wi-Fi well beyond our anticipation, and that young women positively accepts the service. An analysis of web access logs revealed that the users tend to select a content not by its meaning but a location of the link to the contents on the screen.

In order to promote the spread of the service, the development and offer of a software tool which generate web contents automatically from audio/video data that a museum prepared are effective. This is a future subject.

\section{References}

1) A.Damala, I.Marchal, P.Houlier: "Merging Augmented Reality Based Features in Mobile Multimedia Museum Guides", Proceedings of the 21st CIPA symposium - AntiCIPAting the future of the cultural past, 6 pages (October 2007)

2) T.Miyashita, P.Meier, T.Tachikawa, S.Orlic, T.Eble, V.Scholz, A.Gapel, O.Gerl, S.Arnaudov, S.Lieberknecht: "An Augmented Reality museum guide", Proceeding ISMAR '08 Proceedings of the 7th IEEE/ACM International Symposium on Mixed and Augmented Reality, pp.103-106 (September 2008)

3) http://www.minpaku.ac.jp/english/museum/exhibition/videotheque Information Zone, National Museum of Ethnology website

4) http://www.nintendo.co.uk/News/2012/The-Louvre-museum-andNintendo-join-forces-to-release-the-Audioguide-LouvreNintendo-3DS-253622.html, The Louvre museum and Nintendo join forces to release the Audioguide Louvre - Nintendo 3DS (News Release, 10 April 2012)

5) http://www.koozyt.com/solutions/amp/damono?lang=en, DaMoNo - The World of Mitsuo's Daily Calendar, Koozyt Inc. website

6) Kouichi Shichida, Tomoya Ishikawa, Masakatsu Kourogi, Teiichi Nishioka, Takeshi Kurata: "Exhibition Service: User study on Mobile Science-Museum Guide", Proceedings of IEICE-HCG Symposium, pp.457-462 (December 2010)

7) http://www.tnm.jp/modules/r_free_page/index $\cdot$ php?id=168\&lang=en, Applications, Tokyo National Museum website

8) http://www.nmwa.go.jp/jp/information/pdf/ttm_pressreleases.pdf Press Release, National Museum of Western Art, Tokyo, JAPAN (29 March 2010)

9) http://www.w3.org/TR/htm15/, HTML5, A vocabulary and associated APIs for HTML and XHTML, W3C Candidate Recommendation (04 February 2014)

10) National Museum of Japanese History (eds.) : "Musical Instruments Tell Stories" (special exhibition catalogue), National Museum of Japanese History (July 2012) 


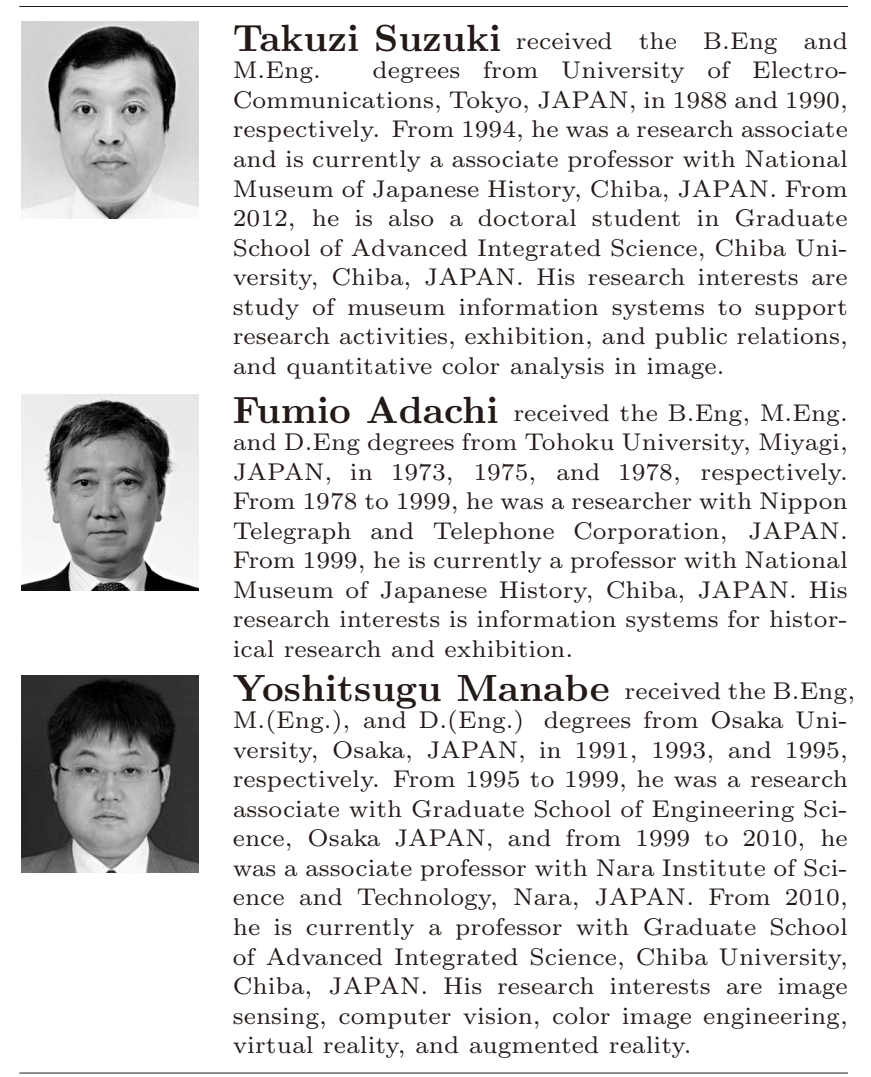

\section{Appendix}

\section{A. Detail of the contents}

\section{A. 1 About the special exhibition}

The special exhibition "Musical Instruments Tell Sto$\operatorname{ries}^{10)}$ " of the National Museum of Japanese History was held for 49 days (closed days were excluded), from July 10, 2012 to September 2. The number of visitors of the special exhibition was 14,841 .

The museum owns one of the best collections of traditional Japanese musical instruments in Japan. They were originally collected by Harutomi Tokugawa (17701852), the 10th generation load of the Kisyu-Tokugawa family. One of major purpose of the special exhibition was to introduce the museum's collection. National Museum of Japanese History had two special exhibitions for this collection in 1992 and 2005.

\section{A. 2 Top Page}

When the top page contents is accessed, a menu to select one from five parts are reproduced. (See app.Fig. 1.) Every part corresponds to $5 \mathrm{PC}$ terminals respectively.

\section{A. 3 Part 1: Research of the pitch of the sound of the standard in gagaku by Haru- tomi Tokugawa}

The table of the contents provided by Part 1 is shown in app.Table 1.

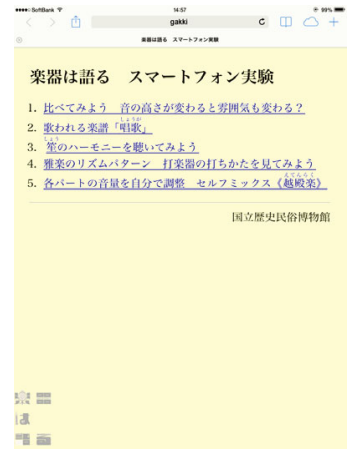

app.Fig. 1 Hardcopy of the top page.

app.Table 1 Contents list of Part 1.

\begin{tabular}{|c|c|c|c|}
\hline content & $\mathrm{A} / \mathrm{V}$ & p.type & description \\
\hline 1/440Hz.mp3 & A & 0:09 & $\begin{array}{l}\text { pitch standard in West- } \\
\text { ern music }\end{array}$ \\
\hline 1/430Hz.mp3 & A & 0:09 & pitch standard in gagaku \\
\hline $1 /$ mixing.mp3 & A & 0:09 & comparison of two pitches \\
\hline 1/pm0.mp3 & A & $0: 30$ & $\begin{array}{l}\text { play of etenraku by nor- } \\
\text { mal pitch }\end{array}$ \\
\hline 1/p3.mp3 & A & $0: 30$ & $\begin{array}{l}\text { play by } 300 \text { cent high } \\
\text { pitch }\end{array}$ \\
\hline $1 / \mathrm{m} 3 . \mathrm{mp} 3$ & A & $0: 30$ & $\begin{array}{l}\text { play by } 300 \text { cent low } \\
\text { pitch }\end{array}$ \\
\hline
\end{tabular}
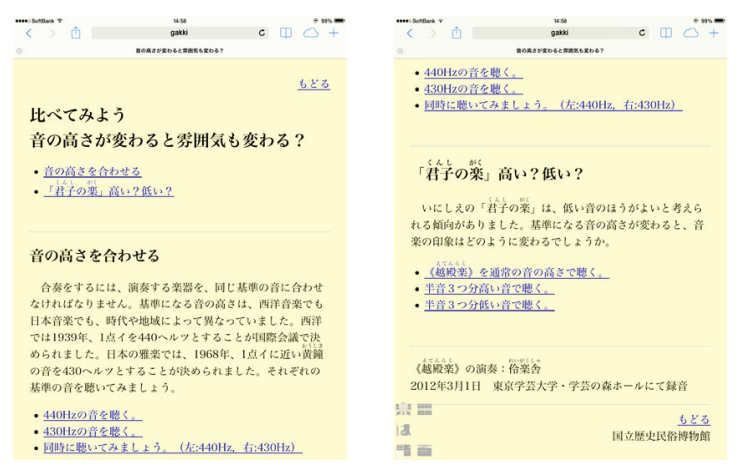

app.Fig. 2 Hardcopy of the Part 1 page.

Harutomi Tokugawa was researched eagerly about the pitch of the sound of the standard in gagaku. In this part, two kinds of contents for understanding the importance of standard pitch are provided. One is contents which hear and compare the difference of two standard tone: $440 \mathrm{~Hz}$ in Western music and $430 \mathrm{~Hz}$ in gagaku. The other is contents which hear and compare the difference of three playing of a part of etenraku, one of famous song in gagaku: normal pitch playing, 300 cent high pitch playing, and 300 cent low pitch playing.

A hardcopy of the Part 1 page on a portable terminal is shown in app.Fig. 2.

\section{A. 4 Part 2: Shōga - a 'singing' score in gagaku}

The table of the contents provided by Part 2 is shown in app.Table 2.

Shōga is 'singing' score in gagaku for description of a melody. In this part, two video contents for introducing 
app.Table 2 Contents list of Part 2

\begin{tabular}{|c|c|c|c|}
\hline content & $\mathrm{A} / \mathrm{V}$ & p.type & description \\
\hline 2/shogaryuteki.mp4 & $\mathrm{V}$ & $4: 26$ & $\begin{array}{l}\text { shōga singing an } \\
\text { ryūteki playing }\end{array}$ \\
\hline 2/shogahichiriki.mp4 & $\mathrm{V}$ & $4: 32$ & $\begin{array}{l}\text { shōga singing and } \\
\text { hichiriki playing }\end{array}$ \\
\hline
\end{tabular}
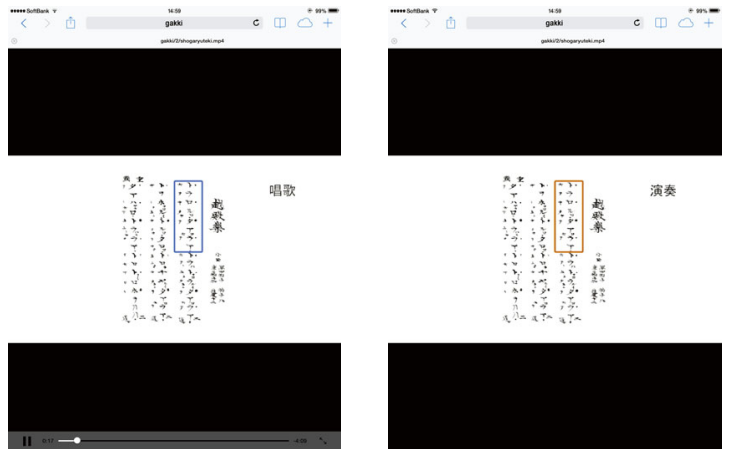

app.Fig. 3 Hardcopy of a playing of the Part 2 contents.

shōga are provided. One is a Shōga of ryūteki, and the other is a Shōga of hichiriki. ryūteki, and hichiriki are kinds of wind instruments in gagaku.

A hardcopy of a playing of a video content in the Part 2 contents on a portable terminal is shown in app.Fig. 3.

\section{A. 5 Part 3: Let's listen to the tone of $s h \bar{o}$}

The table of the contents provided by Part 3 is shown in app.Table 3.

$s h \bar{o}$ is a kind of wind instruments in gagaku. In this part, 15 kinds of icchiku (single tone) and 11 kinds of aitake(chord) can be heard.

On the touchpanel PC terminal, free mixing of any icchiku tones is available. On the other hand, on a portable terminal, only one icchiku tone can be heard simultaneously.

app.Fig. 4 is a hardcopy of Touchpanel PC of the Part 3 contents, and a hardcopy of the Part 3 contents on a portable terminal is shown in app.Fig. 5 .

\section{A. 6 Part 4: A rhythm pattern in gagaku}

The table of the contents provided by Part 4 is shown in app.Table 4.

In this part, a video contents to explain a concept of rhythm pattern in gagaku is provided. The movie shows timing of percussion instrument playing of hayayohyōshi, the rhythm pattern of etenraku. It can be understood that hayayohyōshi has the cyclic structure of quadruple times and four measures.

A hardcopy of a playing of a video content in the Part 4 contents on a portable terminal is shown in app.Fig. 6.
app.Table 3 Contents list of Part 3.

\begin{tabular}{|c|c|c|c|}
\hline content & $\mathrm{A} / \mathrm{V}$ & p.type & description \\
\hline 3/T01.mp3 & $\mathrm{A}$ & $0: 14$ & single tone sen \\
\hline 3/T02.mp3 & A & $0: 15$ & single tone $j \bar{u}$ \\
\hline 3/T03.mp3 & A & $0: 12$ & single tone $g e$ \\
\hline 3/T04.mp3 & A & $0: 12$ & single tone otsu \\
\hline 3/T05.mp3 & A & $0: 13$ & single tone $k u$ \\
\hline 3/T06.mp3 & A & $0: 13$ & single tone $b i$ \\
\hline 3/T07.mp3 & A & $0: 12$ & single tone $i c h i$ \\
\hline 3/T08.mp3 & A & $0: 13$ & single tone hachi \\
\hline 3/T10.mp3 & A & $0: 15$ & single tone gon \\
\hline 3/T11.mp3 & A & $0: 16$ & single tone shichi \\
\hline 3/T12.mp3 & A & $0: 14$ & single tone $g y \bar{o}$ \\
\hline 3/T13.mp3 & A & $0: 15$ & single tone $j \bar{o}$ \\
\hline 3/T14.mp3 & A & $0: 12$ & single tone $b \bar{o}$ \\
\hline 3/T15.mp3 & A & 0:09 & single tone kotsu \\
\hline 3/T17.mp3 & A & $0: 15$ & single tone $h i$ \\
\hline 3/A01.mp3 & A & $0: 12$ & chord kotsu \\
\hline 3/A02.mp3 & A & $0: 13$ & chord $i c h i$ \\
\hline 3/A03.mp3 & A & $0: 13$ & chord $k u$ \\
\hline 3/A04.mp3 & A & $0: 14$ & chord $b \bar{o}$ \\
\hline 3/A05.mp3 & A & $0: 12$ & chord otsu \\
\hline 3/A06.mp3 & $\mathrm{A}$ & $0: 12$ & chord $g e$ \\
\hline 3/A07.mp3 & A & $0: 13$ & chord $j \bar{u}$ \\
\hline 3/A08.mp3 & A & $0: 11$ & chord $s \overline{o j} \bar{o}$ no ju \\
\hline 3/A09.mp3 & A & $0: 11$ & chord $b i$ \\
\hline 3/A10.mp3 & A & $0: 12$ & chord gyō \\
\hline 3/A11.mp3 & A & $0: 13$ & chord $h i$ \\
\hline
\end{tabular}

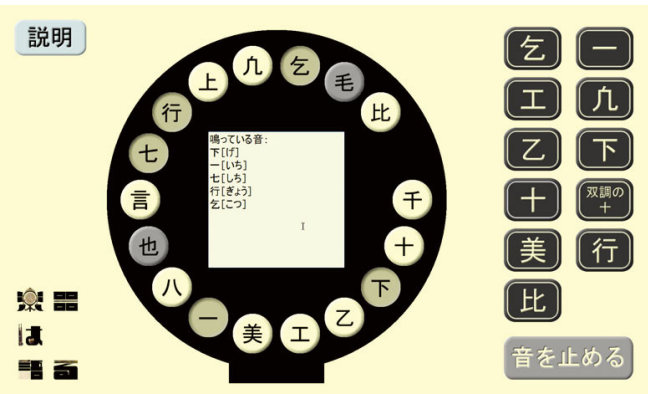

app.Fig. 4 Hardcopy of Touchpanel PC contents of Part 3 - free mixing of $i c c h i k u$ tones.

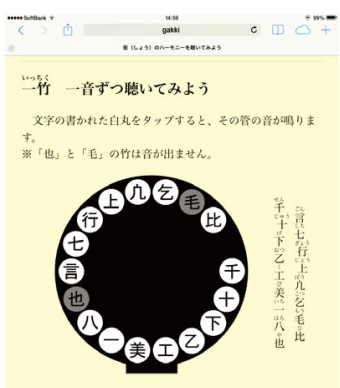

合行 和音を聴いてみよう

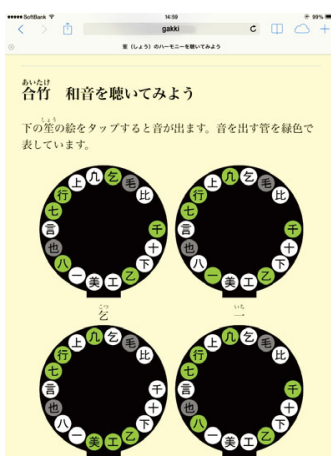

app.Fig. 5 Hardcopy of the Part 3 page.

\section{A. 7 Part 5: A free mixing tool for etenraku playings of 8 kinds of music instruments}

The table of the contents provided by Part 5 is shown in app.Table 5.

In this part, each playing of 8 kinds of musical instruments in gagaku — wind: ryūteki, hichiriki, and sho, string: biwa and sō, and percussion: kakko, taiko, 
and shōko — in etenraku can be selected and heard.

On the touchpanel PC terminal, free mixing of any playings is available. On the other hand, on a portable terminal, only one playing can be heard simultaneously.

app.Fig. 7 is a hardcopy of Touchpanel PC of the Part 5 contents, and a hardcopy of the Part 5 page on a portable terminal is shown in app.Fig. 8 .

app.Table 4 Contents list of Part 4 .

\begin{tabular}{lccl}
\hline content & A/V & p.type & description \\
\hline 4/zundoo.mp3 & $\mathrm{V}$ & $6: 00$ & $\begin{array}{l}\text { introduction of a rhythm } \\
\text { pattern hayayohyōshi }\end{array}$ \\
\hline
\end{tabular}
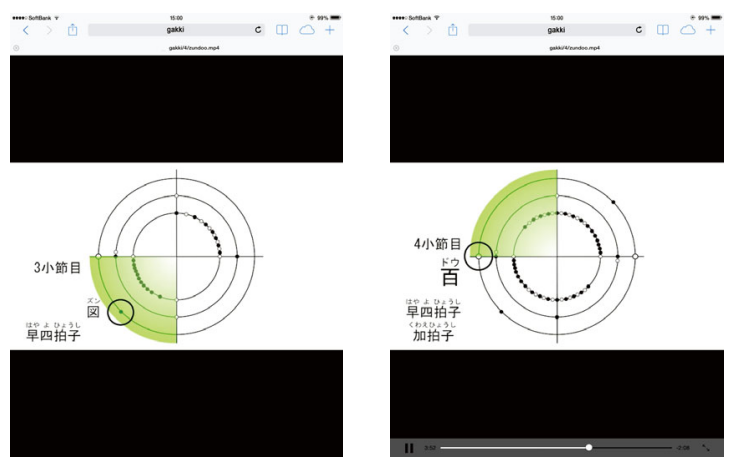

app.Fig. 6 Hardcopy of a playing of the Part 4 contents.

app.Table 5 Contents list of Part 5.

\begin{tabular}{lccl}
\hline content & A/V & p.type & description \\
\hline 5/etenraku.mp3 & A & $5: 35$ & ensemble playing \\
5/ryuteki.mp3 & A & $5: 35$ & playing of ryūteki \\
5/hichiriki.mp3 & A & $5: 35$ & playing of hichiriki \\
5/sho.mp3 & A & $5: 35$ & playing of sho \\
5/biwa.mp3 & A & $5: 35$ & playing of biwa \\
5/so.mp3 & A & $5: 35$ & playing of sō \\
5/kakko.mp3 & A & $5: 35$ & playing of kakko \\
5/taiko.mp3 & A & $5: 35$ & playing of taiko \\
5/shoko.mp3 & A & $5: 35$ & playing of shōko \\
\hline
\end{tabular}

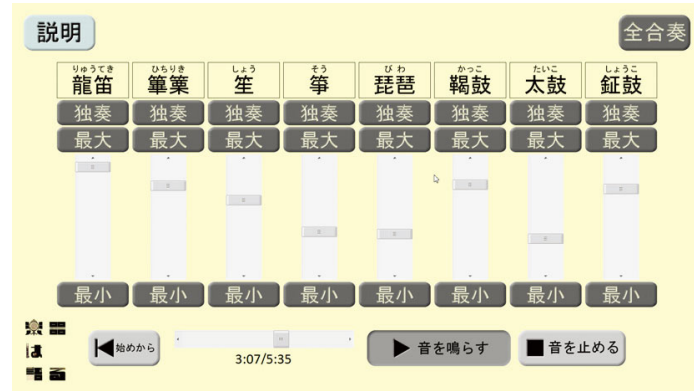

app.Fig. 7 Hardcopy of Touchpanel PC contents of Part 5 - free mixing of etenraku playing.
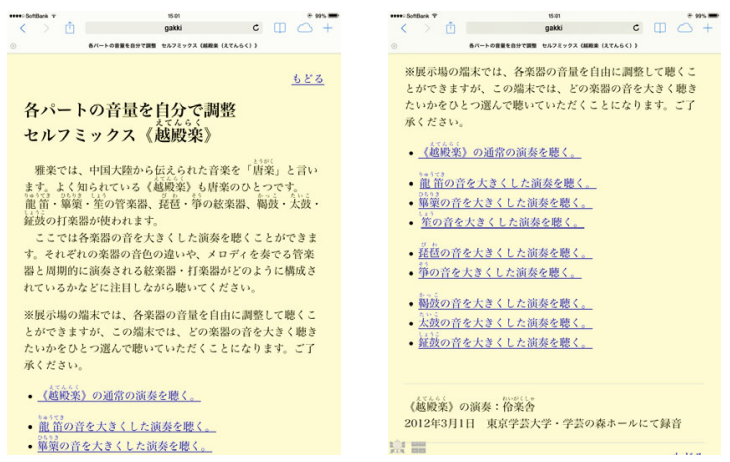

app.Fig. 8 Hardcopy of the Part 5 page. 